------ Raf. J. Sci., Vol. 24, No.5 pp. 87-95, 2013------

\title{
Theoretical High Pressure Study for Evaluation of Spinodal Pressure and Phonon Frequency Spectrum of Silver
}

\author{
Raed H. Al-Saqa Adnan M. Al-Sheikh \\ Department of Physics \\ College of Science \\ University of Mosul
}

(Received 3/10/2012;Accepted 18/2/2013)

\begin{abstract}
Compression versus pressure at room temperature has been evaluated for silver using different equations of states (Birch-Murnghan and modified Lenard-Jones EOSs). A good agreement with experimental data has been observed. Extrapolation of variation of bulk modulus results with pressure has been used to evaluate spinodal pressure. The effect of high pressure on lattice frequency and phonon frequency spectrum (pfs) has been calculated too. A comparison of the present, pfs results show a good agreement with the results of other theoretical published work
\end{abstract}

Keywords: High pressure, spinodal pressure, pfs, EOS.

\section{درلسة ظلربة تهت الضظط العالي لهسلب ضطا المببينول ولف التردد الفونوف الفضة}

\section{الملغص}

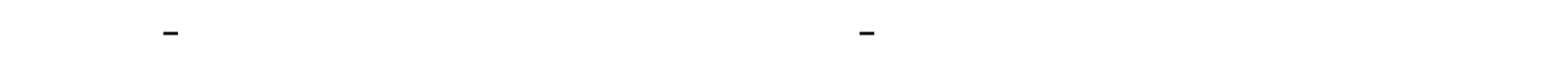
لهسلب النضغطية الفضة تهت الضغط العالي، لُٔلهرت النتائج المستحصلة توافقاً جيدا مع البيانت التجريبية.

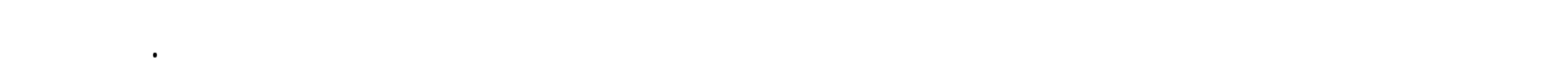

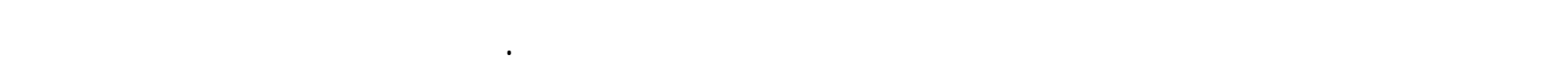
حصلنا عليها لطف التردد الفونوني توافقا جيدامع نتائج البحوث العلمية المشورة.

الكاملت الدالة: الضغط العالي، ضغط للسبينودل،طيف التردد الفونوني،معادلات الحالة.

\section{INTRODUCTION}

Since absolute isothermal pressure-volume measurement is limited to lower pressures, high pressure EOSs can be developed using bulk modulus $\mathrm{B}_{0}$ and its derivative $\mathrm{B}_{0}^{\prime}$, these low-pressure measured quantities are used to extrapolate to higher pressures.

For practical applications, an ideal EOS of state should have the following four merits: (Jiuxun, 2005) 
(i) The energy should be analytic $\mathrm{U}=\mathrm{U}(\mathrm{v})$.

(ii) The EOS should be both pressure analytic $\mathrm{P}=\mathrm{P}(\mathrm{v})$ and volume analytic $\mathrm{V}=\mathrm{V}(\mathrm{p})$.

(iii) It should satisfy the following spinodal condition

$$
B \propto\left(P-P_{s p}\right)^{1 / 2} \text { with }\left(P-P_{s p}\right)=0
$$

(iv) It should have a high energy precision with a simple form and a small number of parameters, and allow one to predict the compression curve for materials at high pressure using only the parameters determined from the experimental data at low pressure. In the following two EOSs which meet these requirements, are used in the present work, as shown below.

(i) Modified Lenard-Jones EOS (Jiuxun, 2005):

$$
\mathrm{P}_{\mathrm{mLJ}}=\frac{\mathrm{B}_{\mathrm{o}}}{\mathrm{n}}\left(\frac{\mathrm{V}_{\mathrm{o}}}{\mathrm{V}_{\mathrm{p}}}\right)^{\mathrm{n}}\left[\left(\frac{\mathrm{V}_{\mathrm{o}}}{\mathrm{V}_{\mathrm{p}}}\right)^{\mathrm{n}}-1\right]
$$

wh

ere $; n=\frac{1}{3} \mathrm{~B}_{\circ}^{\prime} ; \mathrm{B}_{\mathrm{o}}^{\prime}=\frac{d B}{d P}$

$\mathrm{V}_{\mathrm{o}}$-volume at atmospheric pressure; $\mathrm{V}_{\mathrm{p}}$-volume at pressure $\mathrm{P}$

$\mathrm{B}_{0}$ - isothermal bulk modulus at atmospheric pressure

(ii) Birch-Murnaghan EOS (Birch, 1947):

$$
\mathrm{P}(V)=\frac{3}{2} B_{o}\left[\left(\frac{V_{o}}{V_{\mathrm{P}}}\right)^{7 / 3}-\left(\frac{V_{o}}{V_{\mathrm{P}}}\right)^{5 / 3}\right]\left\{1-\left(\frac{3}{4}\right)\left(4-B_{o}^{\prime}\left[\left(\frac{V_{o}}{V_{\mathrm{P}}}\right)^{2 / 3}-1\right]\right\}\right.
$$

\section{Silver under high pressure}

\section{THEORETICAL DETAILS AND RESULTS}

Applying pressure on solid induced a change in specific volume. This change is represented by the ratio $V_{p} / V_{o}$. (Fig.1) shows the relative compression $V_{p} / V_{o}$ for Ag, at different values of applied pressure calculated by using equations (2 and 3 ) with the values of $\mathrm{B}_{\mathrm{o}}$ and $\mathrm{B}_{\mathrm{o}}^{\prime}$ shown in Table-I

Table 1: Values of $B_{o}, B_{o}^{\prime}$ for $\mathrm{Ag}$

\begin{tabular}{|c|c|c|}
\hline $\mathrm{B}_{\mathrm{o}}$ & $105 \mathrm{Gpa}$ & \multirow{2}{*}{ Kennedy and Keeler, (1972) } \\
\cline { 1 - 2 } $\mathrm{B}_{\mathrm{o}}^{\prime}$ & $5.99 \mathrm{Gpa}$ & \\
\hline
\end{tabular}




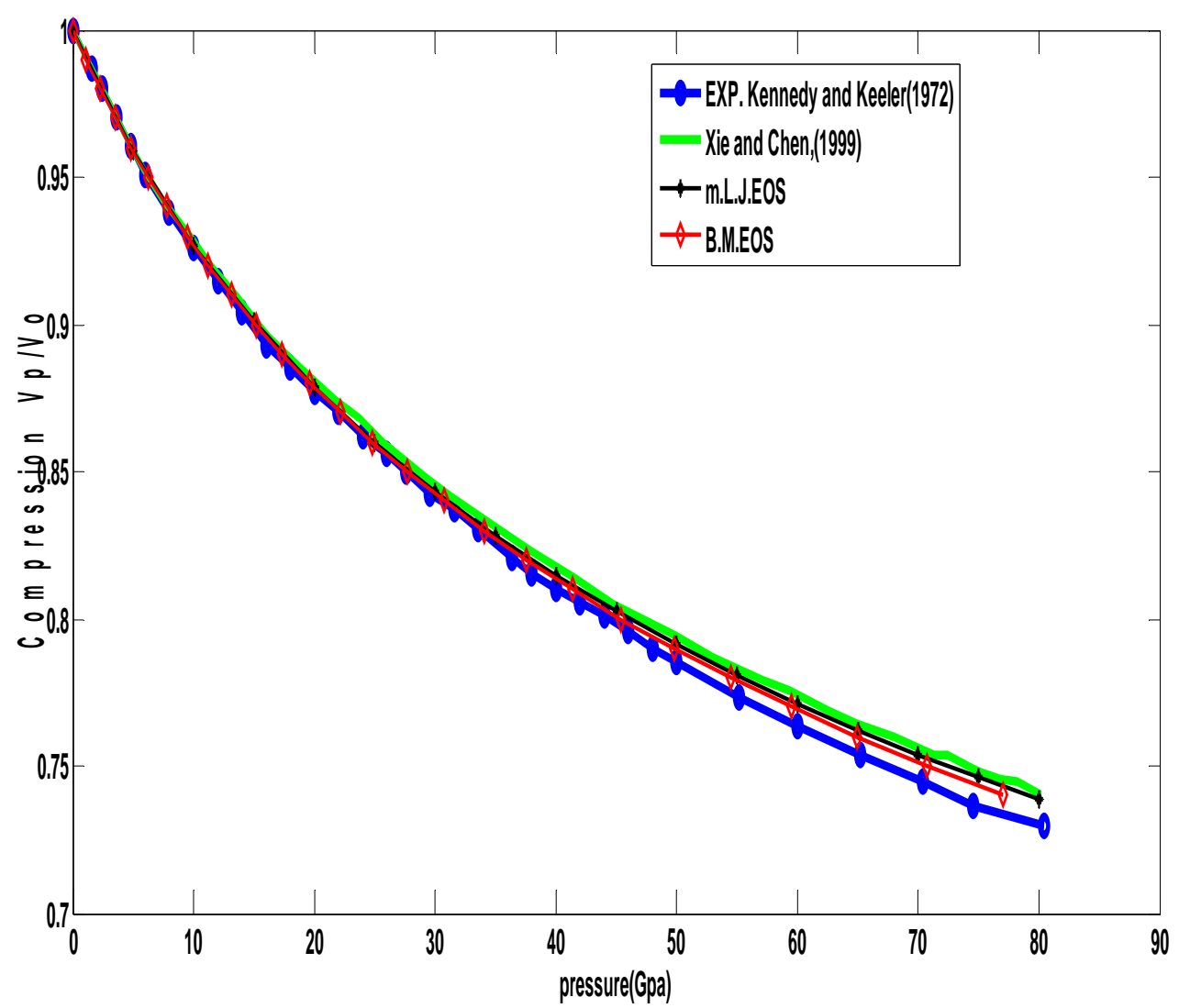

Fig. 1: Variation of $V_{p} / V_{o}$ with pressure for Ag using different EOSs

\section{Bulk modulus under high pressure}

The bulk modulus relates the fraction change in volume to the change in the applied pressure as:

$$
B_{T}=-V \frac{\partial P}{\partial V}
$$

It measures how much pressure is required to compress a substance by a given fraction. A substance with a large bulk modulus is more difficult to compress than a substance with a small bulk modulus.

From Eq.2, 3, and 4, we can express the bulk modulus at pressure (p) by using different EOSs as follows:

The modified Lennard- Jones EOS (mLJ-EOS):

(i)

$$
B_{T}=-V \frac{\partial P}{\partial V}=B_{o}\left(\frac{V_{o}}{V_{p}}\right)^{n}\left[2\left(\frac{V_{o}}{V_{p}}\right)^{n}-1\right]
$$

(ii) Birch-Murnaghan EOS (B-M.EOS) :

$$
B_{T}=\frac{3 B_{o}}{2}\left[\left(\frac{7}{3}\right) \eta^{-7 / 3}-\frac{5}{3} \eta^{-5 / 3}-\frac{9}{4}\left(B_{o}^{\prime}-4\right) \eta^{-3}+\frac{7}{2}\left(B_{o}^{\prime}-4\right) \eta^{-7 / 3}+\frac{5}{4}\left(B_{o}^{\prime}-4\right) \eta^{-5 / 3}\right]
$$


where $\quad \eta=V_{p} / V_{o}$

$B_{T}$-isothermal bulk modulus at pressure $\mathrm{p}$

(Fig. 2) shows the variation of bulk modules with pressure using different EOSs

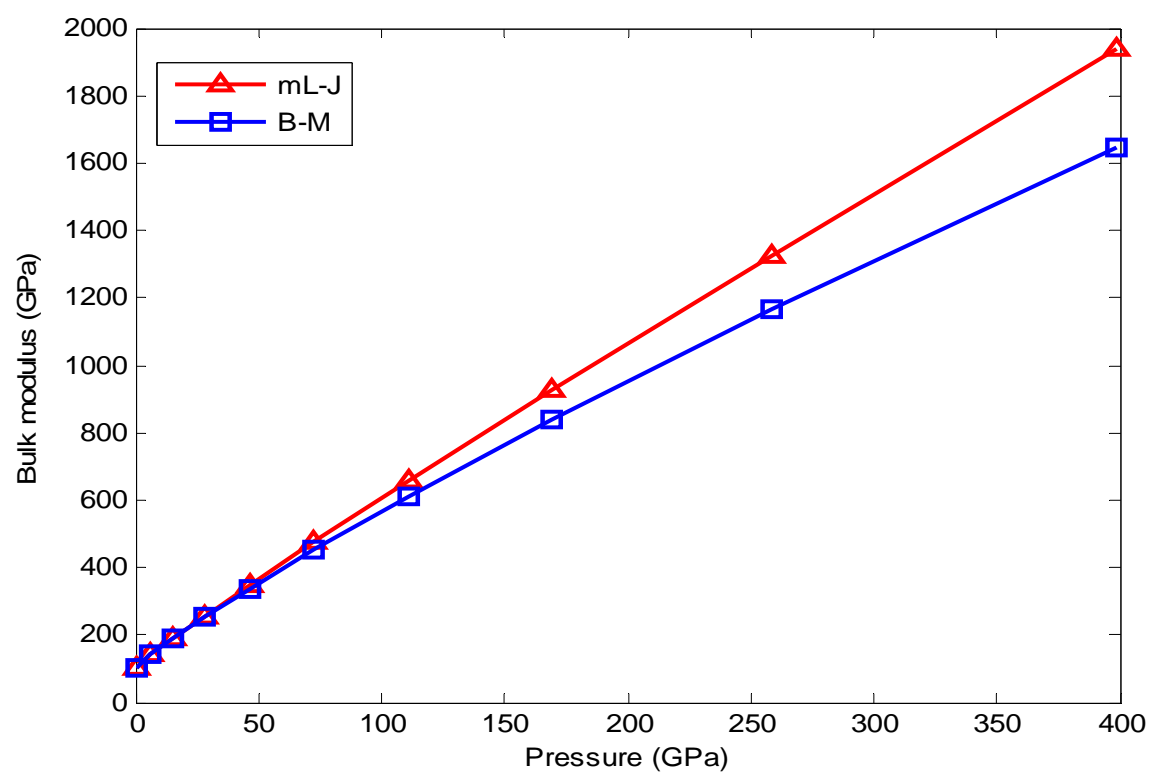

Fig. 2: Variation of the bulk modulus with pressure using different EOSs

\section{Spinodal pressure}

Spinodal decomposition deals with dynamics of phase changes in materials which are caused by transferring the material into an initial state that is not thermodynamically stable (e.g. by rapid cooling, by rapid heating and also rapid pressure change). (Binder and Fratzl, 2001).

Although spinodal pressure is defined as pressure at which $\mathrm{B}=0$. The existing theories of spinodal decomposition are, in mechanistic form, valid and essentially correct, even if a completely unambiguous definition of the spinodal cannot be given (Reiss, 2010; Imre 2007), (Mijbel et al., 2012).

The evaluation of spinodal pressure is a promising approach in the formulation of universal EOS for solids as it is enable to study meta stable state of material at negative pressure.

In the present work, on extrapolating the results shown in (Fig. 2) up to the point where bulk modulus equal zero we obtain an expression for spinodal pressure for Ag as:

$$
P_{s p}=-B_{o} \frac{\partial P}{\partial B}
$$

(Fig. 3a, b) show the values of spinodal pressure for Ag evaluated by combining eq's.5, 6 and 7. 


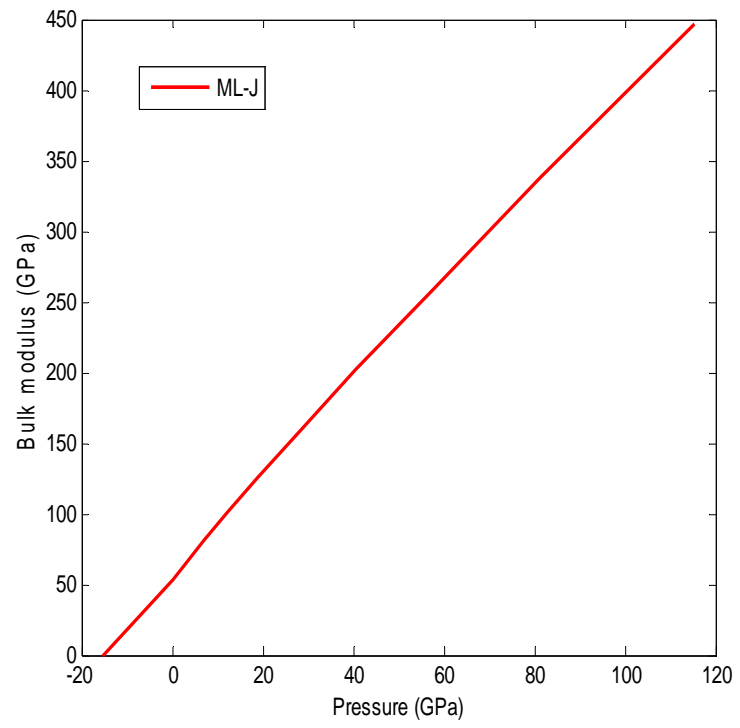

(a)

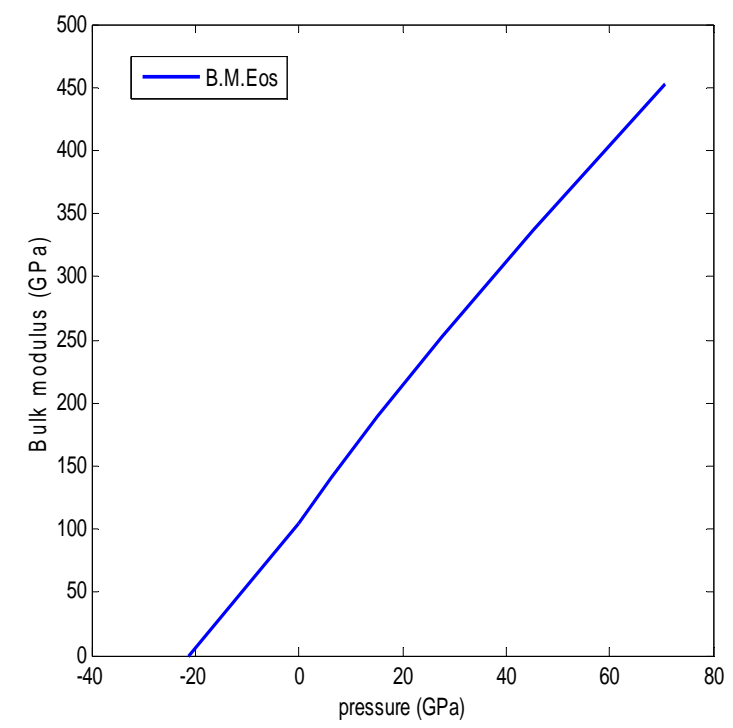

(b)

Fig. 3: Spinodal pressure for Ag by using (a) m.L.J-EOS, (b) Birch- Murnaghan EOS

Table (2) shows a comparison between the values of spinodal pressure for Ag, obtained in the present work with values of $P_{s p}$ given by Jiuxun, 2005 .

Table 2: Comparison of the spinodal pressure values obtained in the present work with reported results.

\begin{tabular}{|c|c|c|}
\hline \multicolumn{2}{|c|}{ Present work } & Jiuxun, 2005 \\
\hline EOS & $\mathrm{P}_{\mathrm{sp}} \mathrm{Gpa}$ & $\mathrm{P}_{\mathrm{sp}} \mathrm{Gpa}$ \\
\hline ML-J. & -20.2 & \multirow{2}{*}{-13.146} \\
\hline B.M. & -22.2 & \\
\hline
\end{tabular}

The difference between $\mathrm{p}_{\mathrm{sp}}$ values shown in literature and that obtained in the present work is attributed to the fact that the present work used first principle approach in evaluation of $\mathrm{P}_{\mathrm{sp}}$ values for $\mathrm{Ag}$.

\section{Phonon frequency spectrum under high pressure}

A change in $V_{p} / V_{o}$ of crystal excites a change in the equilibrium position of the lattice points and consequently a change in the frequency spectrum.

Using Grüneisen approximation (Dlouha, 1964) obtained an expression for the changes in frequencies due to change in $V_{p} / V_{o}$ of crystal as: 


$$
\omega_{p}=\omega_{o}\left(\frac{V_{p}}{V_{o}}\right)^{-\gamma}
$$

where:

$\omega_{p} \quad$ frequency at pressure $\mathrm{p} ;$

$\omega_{0}$ frequency at atmospheric pressure

$\gamma \quad$ Grüneisen parameter $=2.35$ for silver (Taravillo et al., 2002)

While change in the distribution function of the frequencies expressed by

$$
g\left(\omega, V_{p}\right)=\left(\frac{V_{p}}{V_{o}}\right)^{\gamma} g\left[\omega\left(\frac{V_{p}}{V_{o}}\right)^{\gamma}, V_{p}\right]
$$

(Fig. 4) shows Ag phonon frequency spectrum (pfs) at atmospheric pressure (Xie and Chen, 1999).

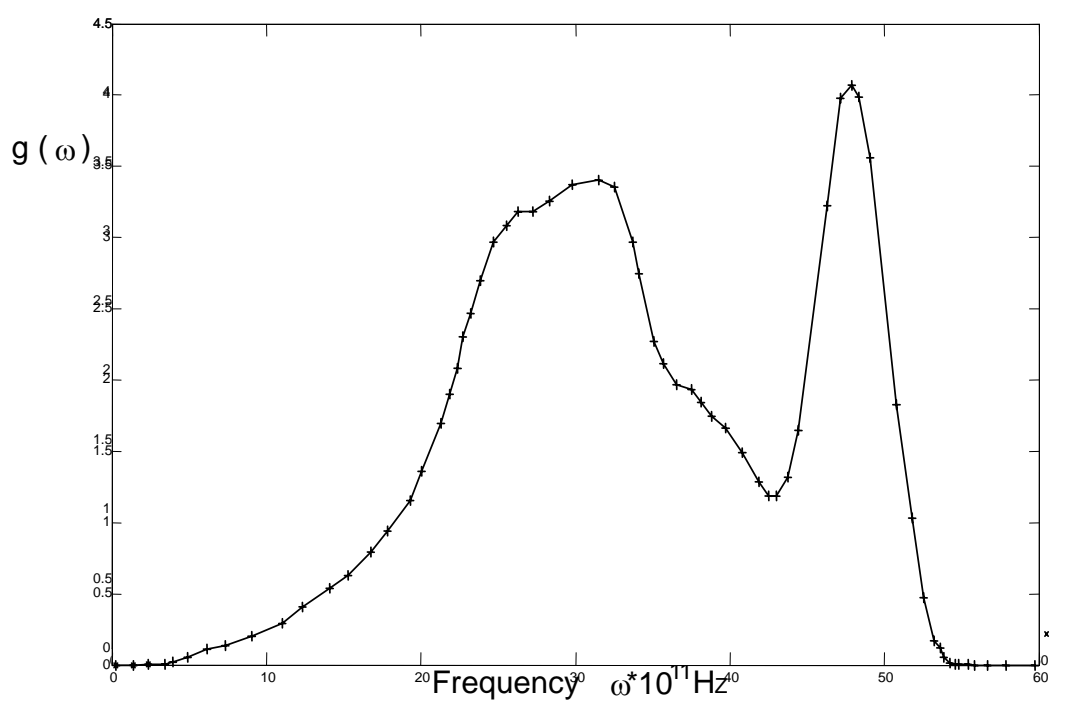

Fig. 4: Frequency spectrum for silver at atmospheric pressure

To compute the effect of high pressure on Ag phonon frequency is spectrum by using different EOSs, the spectrum in (Fig. 4) is analyzed, and different $g(\omega)$ values are recorded for the corresponding frequency values. Then, combining equations 8 and 9 with eq.5 one time and with eq.6 another time.

(Figs. 5a-b) show Ag phonon frequency spectrum obtained by using different equations of state where (Fig.5a) shows the effect of pressure on Ag pfs evaluated by using $\mathrm{mL}$. J. EOS. While (Fig. 5b) shows variation of Ag pfs with the pressure by using B-M EOS 
(Figs. 6a-d) show a comparison between the results obtained in the present work by using mL.J. EOS and B-M EOS, with the phonon frequency spectrum (pfs) under $10 \mathrm{Gpa}$ and $30 \mathrm{Gpa}$ evaluated theoretically by ( Xie and Chen, 1999).

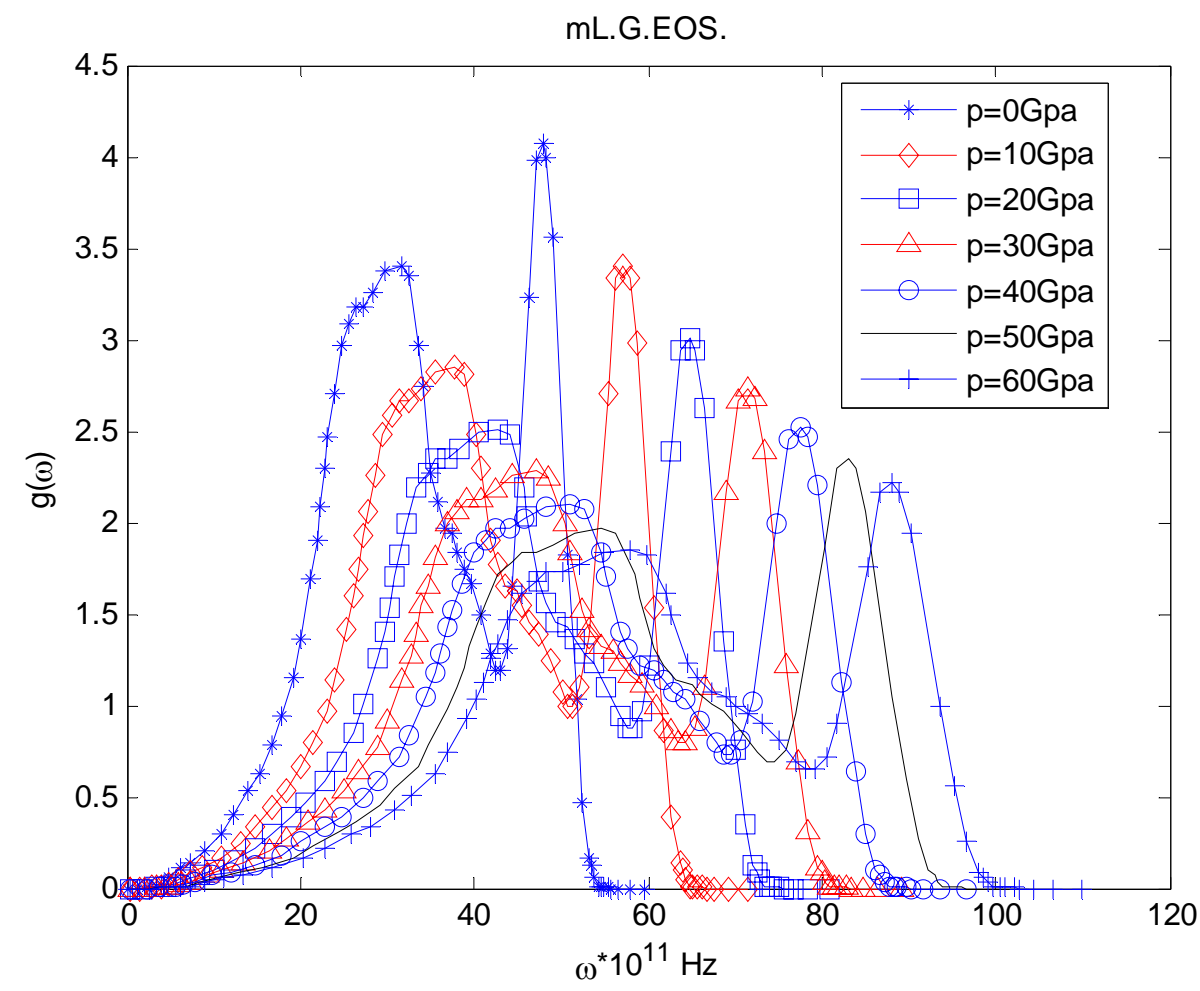

(a)

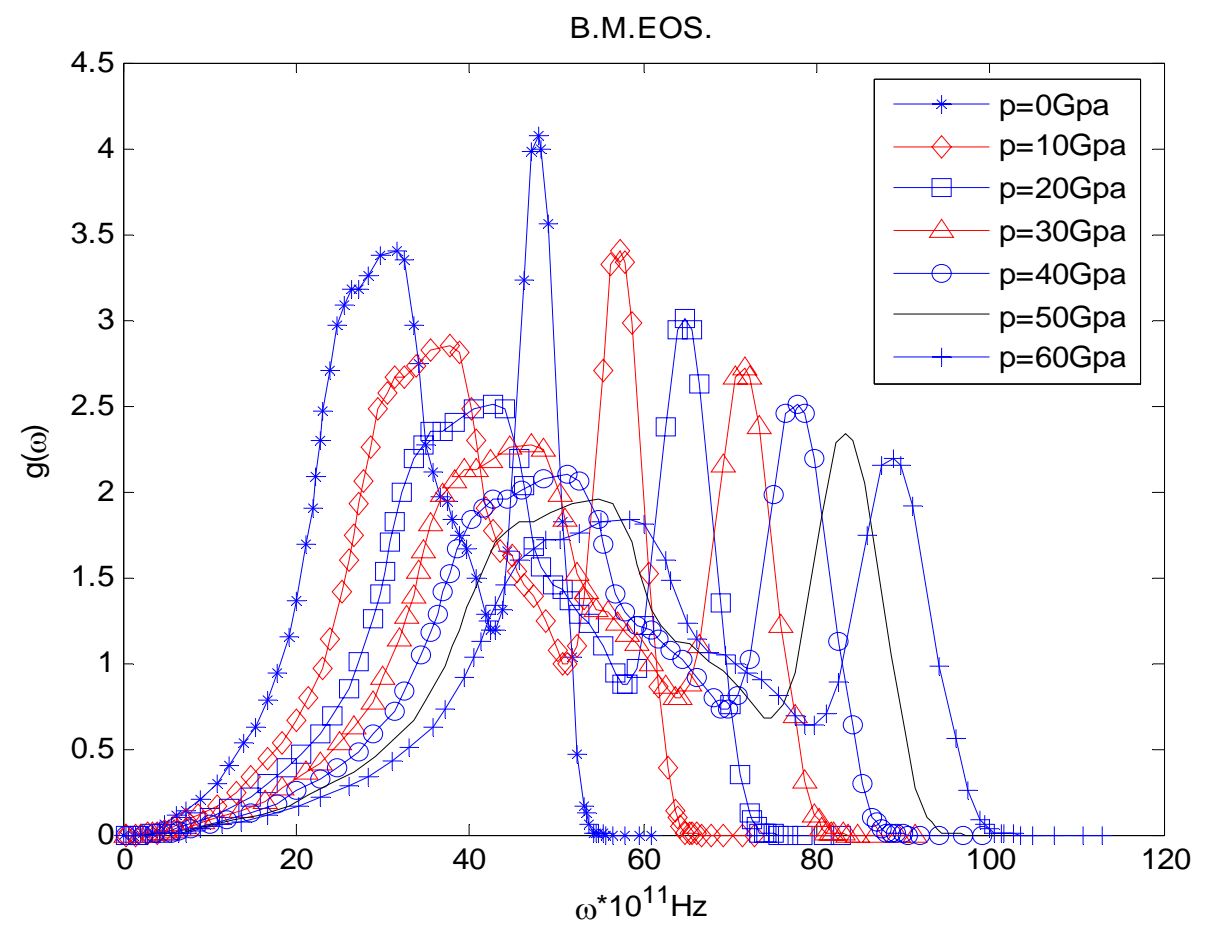

(b)

Fig. 5: Variation of phonon frequency spectrum with pressure by using different EOSs. (a) m. L. J. EOS., (b) Birch-Murgnhan. EOS. 


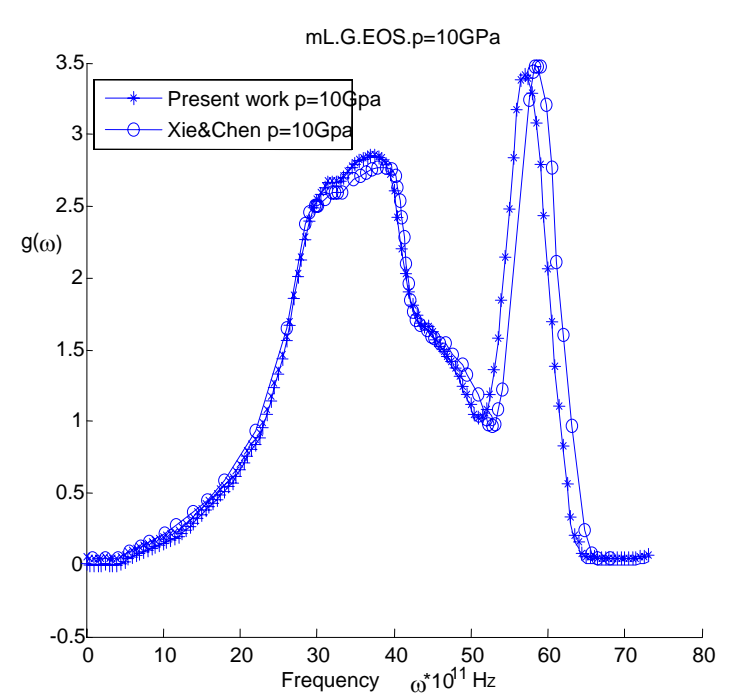

(a)

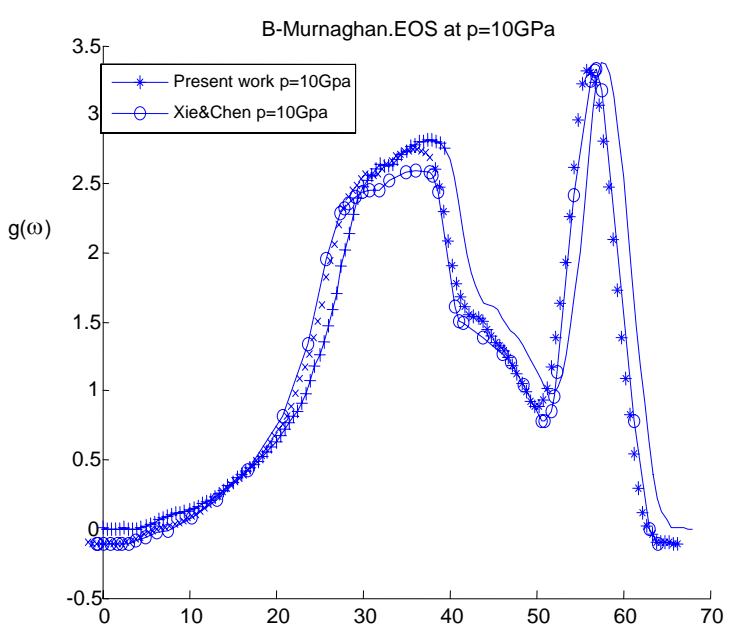

(c)

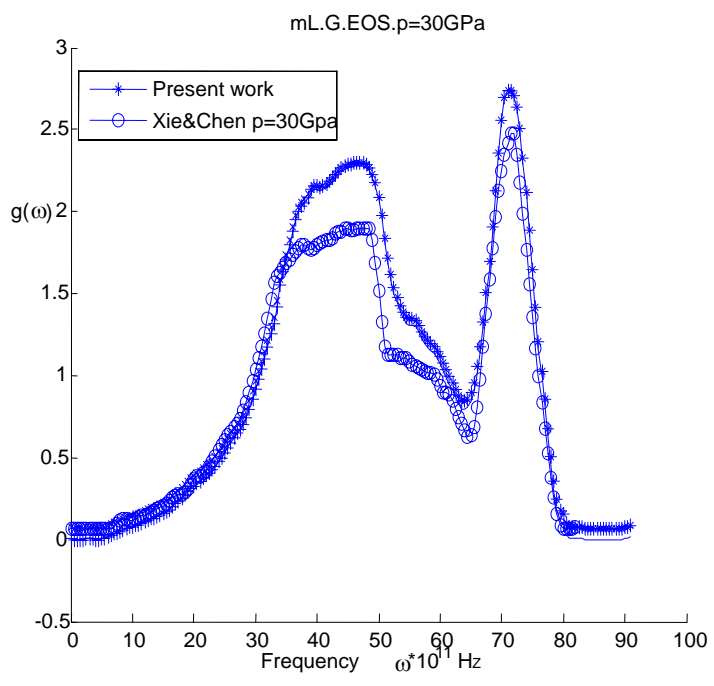

(b)

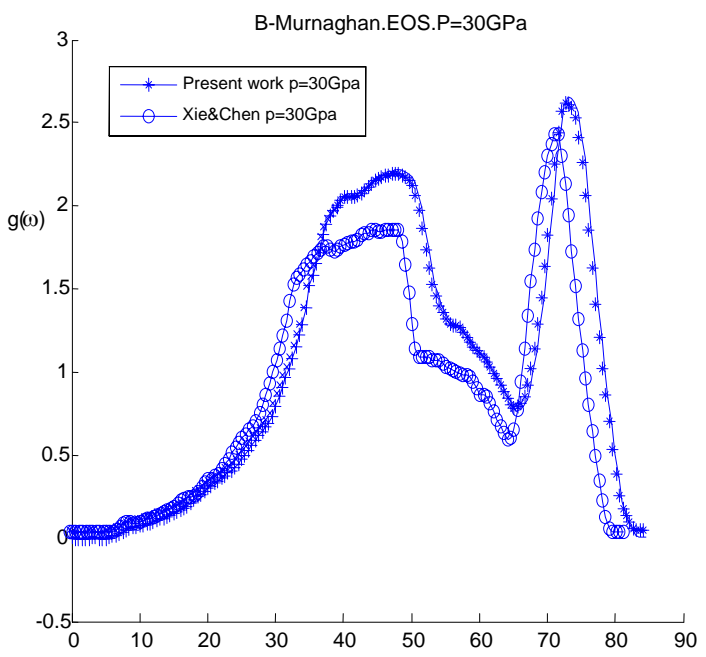

(d) Frequency $\omega^{* 11} \mathrm{~Hz}$

Fig. 6: Comparison of phonon frequency spectrum for Ag under $10 \mathrm{GPa}$ and $30 \mathrm{GPa}$, evaluated in the present work with that reported in (Xie and Chen, 1999).

Although all (Figs. 6a-d) show an excellent agreement between the results of the present work and (Xie and Chen, 1999) results. (Fig. 5b) indicates that mL. J. EOS gives an exact agreement with (Xie and Chen, 1999) results. While (Fig. 6d), shows an excellent agreement with (Xie and Chen, 1999) results. This may be attributed to the fact that mL. J. EOS depends on the atomic potential while B-M. EOS depends on the mechanical finite strain. 


\section{DISCUSSION}

The phonon frequency of $\mathrm{Ag}$ increases with the increase of pressure (Figs. 5a-b) which are consistent with increasing bulk modulus under pressure (Fig. 2). The phonon density of state spreads up to high frequency domain as pressure increases.

Spinodal pressure study is a promising approach to formulate universal EOS of solids. The difference between $P_{\text {sp }}$ values shown in Table-II could be attributed to the fact that the present work used the first principle approach in evaluation of $\mathrm{P}_{\mathrm{sp}}$ values, while (Jiuxun, 2005) used the generalized Lennard- Jones potential.

\section{REFERENCES}

Birch, F. (1947). Finite elastic strain of cubic crystals. Phys. Rev, 71,809-824.

Binder, K.; Fratzl, P. (2001). Spinodal decomposition. In, phase transformation in material. Edited by Kostorz, G., Wiley-VCHVerlgGmbH. Weinheim.

Dlouha, J. (1964). The influence of pressure on the Mössbauer effect. Czech. J. Phys., B 14; 571-579.

Imre, A.R. (2007). On the existence of negative pressure states. Physical Status Sol. (b) 244 (3), 893-899.

Jiuxun, S. (2005). A modified Lennard-Jones type equation of state for solids strictly satisfying the spinodal condition. J. Phys.: Condens. Matter. 17, L103-L111.

Kennedy, G.C.; Keeler, R.N. (1972). "American Institute of Physics Handbook". 3rd ed., New York, McGraw-Hill, section 4, 101 p., Cited in Xie J.; Chen, S.P. (1999).

Mijbil, Z.Y.; Aboud, H.I.; Abdul- Lettif, A.M. (2012). Variation of the structural properties of IV element Nano Clusters due to tensile stress. World J. Condensed Matter Phys., 2, 16-23.

Reiss, H. (2010). The existence of the spinodal, an incompletely solved problem in the thermodynamics of solids. Berichte der Bunsengesellschaft Für Physikalische Chem. 79(11), 943-957.

Taravilo, M.; Baonza, V.G.; Rubio, J.E.F.; Nunez, J.; Caceres, M. (2002). The temperature dependence of the equation of state at high pressures revisited: a universal model for solids. J. Phys. Chem. Solids, 63, 1705-1715.

Xie, J.; Chen, S.P. (1999). Thermodynamic properties and lattice dynamics of silver at high pressure: a first principle study. Philosophical Magazine. B79 (6), 911-919. 